\title{
Instantâneos poéticos na ficção de António Lobo Antunes
}

\author{
Márcia Michelin Laboissière \\ Universidade Federal de Minas Gerais
}

That corpse you planted last year in your garden, Has it begun to sprout? Will it bloom this year? Or has the sudden frost disturbed its bed?

T. S. Eliot, "The waste land"

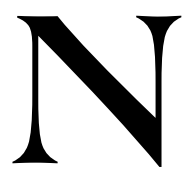

o livro Não entres tão depressa nessa noite escura, de António Lobo Antunes, um fato deflagra a narrativa: a doença cardíaca do pai de Maria Clara. O mal que o levou a uma cirurgia, a expor sua debilidade a olhares médicos e familiares, "sem poder mandar em ninguém", é o mesmo acontecimento que instaura Maria Clara na cadeira de balanço do sótão, no lugar e tempo privilegiado de um narrador ávido de reinar sobre as trevas ao som do estribilho: "Maria Clara é o homem da casa". Ela é a narradora-protagonista que, de súbito, ascendeu ao aposento superior da casa e tem pressa em saber do desejo dos outros - daí talvez a advertência firmada como sobreaviso na capa do livro.

Quanto ao poder de mando da casa, talvez não fosse preciso dizer que Maria Clara tende ao fracasso. Em uma consideração rápida sobre os ganhos econômicos que mantêm casa e família, conclui-se que os negócios do pai envolvem a complexidade de um comércio ilícito, de negociatas com "iugoslavos, pretos e árabes", de relações escusas com olheiros, de administração de depósitos clandestinos de armas, enfim, de transações que talvez tenham sobrevivido como herança portuguesa das guerras de África, que tanto se infundiram no plano da narrativa romanesca de Lobo Antunes. Exceto pela obstinação num desejo de ver resguardada uma família de sua decadência e uma casa da ameaça do desgaste operado pelo tempo, leitor e narradora sabem ser impossível requerer de uma adolescente a continuidade de uma atividade mafiosa.

Sentindo-se perdida de início como gestora dos negócios dessa casa que é também sede de uma empresa suspeita, Maria Clara queira, talvez, 
mais do que evitar uma falência, suprir as falhas de sentido das outras existências que entram na composição de sua própria vida. E essa é a atividade que irá exercer presumindo-se dotada do poder de ocupante de uma cadeira ruidosa que, colocada em frente ao postigo do sótão, dá a ver não só aquilo que transcorre como acontecimento no dia-a-dia dos moradores da casa quanto o que se passa como fantasia na existência mental de cada um.

Assim como a doença e a morte anunciada do pai fazem irromper a narrativa, e, na seqüência, comparecem nela como o lado escuro que concerne à vida e que faz padecer o homem pela consciência do fim que nele aflora, tudo aquilo que é índice de morte ou dos fatos da vida da família, presentes ou passados, que se querem mortos, são convocados a tomarem parte de uma história, ou seja, são requeridos como testemunhos de acordo com a intenção de Maria Clara de fazer algo parecer como verdade, mesmo ao custo de uma insondável submersão na noite escura. É também no sótão que Maria Clara encontra ruínas às quais aplicará seu olhar para fazê-las falar do sentido da vida que, supostamente, nelas ainda soluça. Desses restos fazem parte um cavalo de pau, um armário com caixas contendo cartas, fotografias, postais, medalhões, bibelots de pobre, andorinhas de gesso e uma esfinge cromada, formando uma coleção que - ao que parece ser o julgamento dessa narradora - seria considerada "obnóxia" pela mãe de Maria Clara e jamais aceita no meio de sua prataria ${ }^{1}$. Vale lembrar que, na seqüência narrativa, a apresentação dessa coleção de restos é acompanhada de uma lembrança do pai em camisola cor-de-rosa de hospital exigindo sua dentadura postiça. E, assim como a dentadura salva o pai da sua decrepitude, os restos encontrados no sótão, os pedaços banidos de sua vida, comunicar-lhe-iam um sentido.

A história indicial da origem familiar do pai, Luís Filipe, é montagem de dados como legendas de fotos escritas com letras sumidas, pequenos detalhes fisionômicos, uma certidão de nascimento onde Maria Clara enxerga uma rasura no campo do nome da mãe. Informações esparsas que dão lugar a uma efabulação sem limites em cujo resultado final aparece uma casa que não se sabe onde - se em Birre, Alcabideche ou Alcoitão -, habitada por um professor que é o pai do pai, uma inválida, esposa do

\footnotetext{
${ }^{1}$ Ver ANTUNES, 2000. p. 32.
} 
professor, uma neta órfã, a Leopoldina, e uma criança de nome Luís Filipe, que, de tempos em tempos, quando sai do internato, ali aparece para uma visita. O papel de mãe do pai Maria Clara preenche com a figura da Adelaide. A mesma Adelaide que viria a ser uma empregada da família com a única função de cuidar da mãe da mãe de Maria Clara. Ao fim, desse elenco imaginário da bastardia paterna, destaca-se Leopoldina, uma espécie de alter ego de Maria Clara que tem com ela um avô em comum.

Se, nessa síntese, a história parece confusa, na sucessão de enunciados do livro de Lobo Antunes, também não há garantia de um sentido da ordem para o leitor. E, quanto mais a narradora insiste na coerência narrativa, procurando confirmar com as pessoas de seu entorno suas próprias conclusões - que, aliás, nunca são corroboradas - ou dando prosseguimento à narrativa com suprimento de lacunas por elementos imaginados, mais as possibilidades de significação vão se proliferando, mais difícil ainda se torna para o leitor decidir-se sobre a verdade ou a falsidade dessa história. A certa altura a narradora opta por construir outra história em que o segredo revelado é, do mesmo modo, uma origem humilde que, contudo, não cabe mais ao pai, e sim à mãe. Ainda mais inverossímil, esse outro enredo é também abandonado; e, em dado momento, é a própria narradora que confessa seu poder de inventividade em relação aos desdobramentos narrativos de suas histórias ou mesmo aos personagens que nelas têm um papel. Assumindo a voz analisanda no decorrer de uma sessão, Maria Clara teoriza sobre o fingimento sincero que envolve o ato psicanalítico - e, por extensão, o próprio pacto ficcional no qual está também envolvida:

invento sem parar esperando que imagine que invento e desde que imagine que invento e não acredite em mim torno-me capaz de ser sincera consigo, é certo que de tempos a tempos, para o caso de me supor honesta, lhe ofereço uma nuvem amarela ou uma nuvem castanha e uma mão-cheia de pardais em lugar da verdade ${ }^{2}$.

A começar pela consideração dessa indecidibilidade sobre a verdade, a obra de Lobo Antunes, ou, se assim pode-se dizer, a narrativa de Maria Clara, atende aos parâmetros de estabelecimento da prosa ficcional moderna. Os enunciados sucedendo-se em liberdade vão de

\footnotetext{
${ }^{2}$ ANTUNES, 2000. p. 365.
} 
encontro à expectativa do leitor, que ao fim desconfia do suceder dos próprios acontecimentos. A indecisão atinge também a mudança de pontos de vista narrativos. Inicialmente indicada por uma apresentação gráfica diferenciada, pela demarcação do uso do itálico ou do parêntese, a voz do outro, que não a da narradora, vai, ao longo da obra, tornandose indistinta; o que faz desacreditado aquilo que teria sido a princípio um protocolo de leitura. Pode-se considerar que essa "irrealização narrativa", que ativa no leitor um estado de suspeita e que confirma a desarticulação básica da prosa moderna, é posta em curso pela chamada poética da negatividade. Maria Alzira Seixo aplica o conceito de reatualização narrativa na avaliação do que na atualidade apresenta-se como impossibilidade de dar continuidade seqüencial a um relato, impossibilidade essa decorrente da "irrupção constante de vozes, reveses, tempos, incidentes, perspectivas e símbolos"3. A poética da negatividade orienta também a narrativa no sentido de uma incompletude, assim como propõe que a ficção venha a se negar como ficção. Essa negação reside tanto no insucesso de Maria Clara como narradora, que falha em contar histórias que sejam um seguro desenrolar de suas experiências no tempo, quanto na sua estratégia discursiva de um relato que se apresenta a certa altura como um diário.

Ao referir-se à sua escrita como um diário, Maria Clara parece querer fugir a uma provável desorientação que lhe causou a tentativa obcecada de apreensão do sentido da realidade que a cerca. Aparentemente seu mundo teria se esvaecido, e o movimento que poderia ter sido um simples devir expulsou dele o desenrolar dos dias, e misturou aos acontecimentos outros acontecimentos, pensamentos espúrios e reflexões que lhes eram estranhas. A luz que almejava trazer àquilo que de início pareceu-lhe uma casualidade à espera de uma investigação dissipou-se em meio à noite escura que é a ruína das condições do real. Buscando escapar ao fracasso, Maria Clara esforça-se por fazer acreditar que sua escrita seria a escrita de um diário. Ela faz parecer que as interferências de vozes estranhas ao texto vêem de fato de outras fontes elocutivas; em certos momentos confessa que ofereceu o diário para que a irmã fizesse nele seus apontamentos. Se o diário quer ser, por definição, uma coleção de insignificâncias e a

\footnotetext{
${ }^{3}$ SEIXO, 2002. p. 399.
} 
ausência da obra ${ }^{4}$, é certo então que o fracasso estaria evitado. Mas talvez Maria Clara tenha buscado esquecer de que não há salvação possível do dia pela escrita, mesmo que esta se autodenomine diário.

Uma análise da narradora requereria por certo uma conclusão sobre a impossibilidade do luto. Maria Clara sente próxima a morte do pai, busca reconstituir sua memória, e prossegue persistindo na perda pelo ato narrativo repetitivo de retorno a um mesmo lugar. Tal veredicto da escrita melancólica acrescenta-se à percepção dos procedimentos da poética da negatividade.

Suponha-se, contudo, que não se queira de fato entrar tão depressa nessa noite escura. À injunção "não entres tão depressa", poder-se-ia acrescentar o sentido latente de seu imperativo hipotético: "para que te acostumes à escuridão". Evitar-se-ia assim o tropeço nos restos deixados no sótão? É certo que, ao menos, seria mais garantida a adaptação do olho à escuridão. Antes o mover-se na escuridão do que a fixidez pelo fascínio da sombra.

Assim, mais do que uma advertência, o "Não entres tão depressa nessa noite escura", pode ser tido como um convite à percepção através da escuridão. Não uma superação da cegueira, mas um tratado sobre a visão dos cegos. Nesse sentido, a imagem do avô jogando xadrez seria emblemática. O avó cego, jogando xadrez, não pode ser enganado; enxerga as peças com as mãos, contornando-as sem as derrubar. Mas, para além do tabuleiro com seu jogo armado, o avó perdeu o desejo da visão, tropeça com freqüência, submete-se à zombaria das netas, expõe-se ao ridículo, sujando-se na hora das refeições. Quando a narradora, em seu fingimento, sugere a voz do avô, é assim que ele manifesta sua inabilidade em lidar com a cegueira:

os sapos numa espécie de baile investigando perigos, a bengala a picar o sobrado, uma gota de aflição na testa, quantas vezes pensei que vivia cercado de ravinas, de abismos, do soalho que faltava a menos de um passo, de degraus que tinha de haver e não havia

\footnotetext{
${ }^{4}$ A possível definição é apresentada por Blanchot ao sugerir que o autor de um diário tem a pretensão de resguardar-se do perigo da escrita. Mas é o próprio Blanchot que também indica os motivos pelos quais essa pretensão é ilusória. BLANCHOT, 1989. p. 193-198.
}

${ }^{5}$ ANTUNES, 2000. p. 383. 
Um pequeno poema, "as patas da gata dos penhores" ${ }^{6}$, pretende revelar o segredo. Encastoado na narrativa, inscrito entre fragmentos que servem à apresentação da avó de Maria Clara - viciada em jogos e com mania de penhorar jóias como forma de alimentar o vício - o poema descreve um passeio feito às cegas, mas de uma eficiência mágica e surpreendente:

havia imensos relógios na loja garantindo horas mais felizes, alianças baratas e prateleiras com objectos a que faltava tinta, doirados ou de cobre como as criadas gostam, através dos quais uma gata clandestina passeava com desdém a meticulosidade das patas?.

No desdém meticuloso de um caminhar, evitam-se e levam-se à conta os objetos. Consideração e superação do mundo sensível; não para operar através dele uma síntese que indique os caminhos não obstruídos, não para mapeamento do caminhar possível numa desatenção aos objetos, mas para informar que não é possível desconsiderar o que toca aos sentidos.

O trecho citado é também abertura para a consideração de uma poética em paralelo que orienta a narrativa para além da negatividade posta pela indecidibilidade, pela coleção de fragmentos, pela inconclusão, pela linguagem das elipses e paradoxos sob orientação da descrença, da confusão dos tempos e a desarticulação do enredo. Sustentado por uma poética da consideração da dimensão episódica dos acontecimentos, o poema indica também uma inscrição pontual no transcurso de um tempo cronológico em que os relógios não só têm êxito na orientação em relação a uma demarcação precisa de um tempo como garantem uma existência mais feliz.

A felicidade pode residir ainda na suspensão do tempo que torna sublime até mesmo a desmedida da morte. Uma das supostas formas da morte do pai apresentada por Maria Clara figura como a descrição de um quadro que absolutiza o instante da morte fixando o corpo morto num gesto de despedida perpétua:

${ }^{6}$ Essa sentença, atribuída neste ensaio a um "poema" como se fosse seu título, na verdade não acompanha o trecho citado a seguir. Ela encontra-se em meio a uma reflexão sobre a atitude do avô no jogo de xadrez. Ver ANTUNES, 2000. p. 20.

${ }^{7}$ ANTUNES, 2000. p. 17. 
e o adeus a concordar connosco, não existe o tempo nem dor nem inquietação de qualquer espécie, somente o facto do corpo haver deixado de lhe pertencer assistindo a si mesmo e à gente naquele adeus que se tornou perpétuo, o cabelo deixou de ser cabelo, madeixas pegadas à testa por um óleo de cansaço os ossos que o pijama impede de se espalharem no lençol, um joelho que se contrai sozinho e na extremidade do joelho o pé inchado e agudo8.

Na suspensão momentânea do tempo, um assassinato pode se dar à apreciação estética, e ser transposto para o poema que dá visibilidade panorâmica à suposta cena da morte de Leopoldina:

de bruços no chão, qualquer coisa na blusa como um canivete ou uma faca, um brilhozito de sangue em que ninguém repara e a nuvem bordejada de sol na vertical dos pinheiros, mirando-te da janela não uma hora, uns minutos, prometo-te que uns minutos de cacaracá até que a morte a dissolva.?

E, noutro dos quadros instantâneos, a morte pode ser despossuída da morbidez adquirindo o cheiro da pura ausência:

saúde da agonia e depois este cheiro que pela primeira vez não é um cheiro de pobre e não se tornou por enquanto o cheiro da morte, apenas o que principia a constituir o cheiro da ausência, o seu correio sem que ninguém o abra, o fato a chegar da limpeza a seco no invólucro com o nome e o endereço da loja e abandonado nas costas do sofá ${ }^{10}$.

A ironia pode também estar presente na descrição momentânea dos fatos da morte. Assim o quadro do sepultamento, em geral limpo e de mau gosto, passa a ser composto de um detalhe da representação infantil que se acrescenta à redução ritualística da morte.

os homens já à espera, as coroas alinhadas com as suas fitas de pêsames, uma nuvenzinha redonda

porque não uma nuvenzinha redonda?

\footnotetext{
${ }^{8}$ ANTUNES, 2000. p. 200.

${ }^{9}$ ANTUNES, 2000. p. 349.

${ }^{10}$ ANTUNES, 2000. p. 201.
} 
e de bordos prateados do sol viajando para leste, os guardas prosseguindo a vigia no arco da capela, tudo de facto simples, asseado, rápido a partir do momento em que soldaram a tampa não perdendo um pingo sequer ${ }^{11}$.

Revalorização das dimensões mínimas do tempo e dos acontecimentos o poema é também abertura para o conhecimento do mundo. No corpo da obra, o poema é um óculo da narrativa. É o que permite a passagem do som e da luz iluminando as coisas do mundo e é, outrossim, o lugar que dá a ver e a ouvir o mundo - assim como o postigo do sótão é abertura que permite ver e ouvir sem que se abra a porta. O poema é um incidente, um "subgênero", mencionado em caixa baixa como protocolo de leitura na folha de rosto do livro. E é também a mimesis de um episódio de temporalidade particular e espacializada a partir do qual a narradora experimenta sua existência no mundo.

Do malogro de uma laboriosa busca de sentido, da frustração da tentativa de reencontrar o encadeamento dos fatos de uma história, narradora e leitor logram a felicidade do encontro com o poético a cada momento em que, de um mundo imóvel feito de pedaços de retratos empalidecidos e de plantas domesticadas de um jardim bem cuidado, eclode uma imagem diferente do que deveria ser. Instantâneos da realidade da vida poética das coisas do mundo dão-se a conhecer pela positividade de uma imaginação criadora e consciente de que nem mesmo os vermes, mensageiros da morte que metem o nariz na vida, poderiam conhecer o sentido daquilo que arruinaram. Na narrativa é a voz de Leopoldina, pedindo para que a deixem permanecer como um resto do passado, que informa sobre a determinação de Maria Clara em extrair das trevas uma realidade das coisas desapercebidas, desaparecidas, ou transfiguradas pela ação do tempo:

dúzias de focinhos nos vão roendo ao roerem o tempo, não se incomode comigo, largue-me, esqueça-me

eu disse nos vão roendo ao roerem o tempo, roendo a que não desiste de procurar, de ler ${ }^{12}$.

${ }^{11}$ ANTUNES, 2000. p. 203.

${ }^{12}$ ANTUNES, 2000. p. 124. 
A extensa prosa, que é também caderno de poemas, sustenta-se por essa competência da imaginação criadora de uma narradora que, não sendo feliz em imaginar sentidos, mostra-se hábil em dar corpo a leves sinais de sons, cheiros e imagens. Com o ardor lírico das brincadeiras de uma criança que não se deixa imobilizar pelo temor infantil, Maria Clara não cessa de querer criar até os últimos instantes de sua narrativa, e recorre às lembranças que remetem inclusive aos jogos de invenção de si própria:

não podia parar, sou uma fada com uma varinha de cana e uma estrela de papel de seda com um dos ângulos dobrado, pintei os olhos e a boca no toucador da minha mãe e mais fada ainda, a brilhar, embora uma criança que não era eu nos limos do lago, uma estranha que não vira nunca, o tal homem da casa de que a minha mãe falava com centopeias e joaninhas e escaravelhos no bolso a caminhar no escuro apavorada com o escuro, a adormecer de luz acesa ${ }^{13}$.

Assim, tal como as fadas ou os gatos quase cegos dessa narrativa, Maria Clara prossegue, numa crença fenomenológica nas virtudes daquilo que lhe alcança os sentidos, construindo o seu mundo. O que não significa que o texto segue operando, ao modo kantiano clássico, sínteses dos elementos do mundo sensível que preparam o conhecimento desse mesmo mundo. Os resultados dessa reconstrução das coisas do mundo mais se assemelham aos frutos do conhecimento alegórico benjaminiano, que se apropria dos elementos do mundo atribuindo constantemente novos valores aos detalhes. Some-se a isso o exercício estético da imaginação criadora e tem-se constituída a poética, seguida pela narradora, da revelação das coisas em seu instante de personalidade. Criam-se assim, como no seguimento abaixo, instantes poéticos de uma vida essencial que fazem calar a prosa:

quantas vezes, à noite, me acontece escutar alguém que se aproxima e afasta

nem nos sorrir da estrada, ainda cuidei que o meu pai e vi os objetos à espera na ansiedade das coisas, suspendi-me junto à cama na esperança de encontrá-lo porém em vez dos passos e do metal da fechadura o batente ou pode ser que os ramos quando a lestada abranda ${ }^{14}$.

\footnotetext{
${ }^{13}$ ANTUNES, 2000. p. 546.

${ }^{14}$ ANTUNES, 2000. p. 128.
} 
Outros tantos poemas instantâneos revelam igualmente a ansiedade das coisas por meio de imagens que, antes de serem representações sensíveis daquilo que se vê, são verdadeiros acontecimentos objetivos que revelam às personagens a mobilidade dos objetos do mundo que normalmente não se dá a perceber. Assim, à mesa de um jantar em família, era possível observar "um guardanapo invisível que ia tombar na toalha, uma cadeira direita que ia arredar-se sozinha e um isqueiro que iluminava entre portas a indiferença de um morto" 15 .

Por mais que a mobilidade desse mundo indique a fluidez do imaginário onírico, Maria Clara sabe que é preciso estar acordada para poder sonhá-lo. Ondas e palmeiras encarregam-se de despertá-la à noite para fazê-la ouvir em segredo o ruído das coisas que não são ou que o foram há tempos:

não pedia auxílio, não chamava ninguém, limitava-me a escutar o Tejo e os ramos em torno do Casino inventando uma brisa que não existe em julho e uma desordem de morcegos que o rio despedira há séculos para as faldas da serra ${ }^{16}$.

Tordos, goivos e freixos encarregavam-se também de alimentar o sonhar acordado de Maria Clara. Mas, se sua consciência se fixasse em seu próprio ser por algum sofrimento do corpo, o tempo retomaria seu transcurso normal e os ramos quedariam na sua imobilidade vegetal. Neste caso, o menino de barro - uma estatueta que habita o lago dos jardins da casa do Estoril freqüentando a narrativa com liberdade de uma personagem real -, valendo-se de sua humanidade inconteste, deveria encarregar-se de recuperar os sentidos de Maria Clara para a apreciação do mistério do mundo. O poema abaixo registra o movimento dos sentidos entre a vigília e o sonhar acordado:

entre a febre dos dentes e o lodo das insónias, permanecer durante horas à superfície do cansaço a ver os números a mudarem no despertador eléctrico sem nenhum freixo, nenhum sopro de canteiros, nenhum desses ímpetos do menino de barro que de súbito, no escuro, se inclinava para a frente ${ }^{17}$.

\footnotetext{
15 ANTUNES, 2000. p. 184.

${ }^{16}$ ANTUNES, 2000. p. 196.

${ }^{17}$ ANTUNES, 2000. p. 449.
} 
O escuro é um outro fator que provoca a vida instantânea do que foi dado como morto. Assim, na penumbra da atmosfera noturna, flashs de atos cotidianos confirmam a possibilidade de extrair das trevas a vida desaparecida dos mortos. Porém, tudo se põe a perder no ramerrão do despertar diário da casa bem provida de empregados que colocam em evidência o decurso do dia. Veja-se nesse encontro com os seres desaparecidos, ou quase, o temor pela sua proximidade seguido do lamento pela perda do contato com o elemento sobre-humano:

Quantas vezes, à noite, me acontece escutar alguém que se aproxima e afasta nos goivos e não me atrevo a chegar à janela por receio dos mortos

qualquer coisa me diz ao acordar que são os mortos lá fora

o senhor general e o presidente Krüger a falarem de Moçambique julgando-se numa varanda em África, o meu avô que arruma as peças de xadrez no caramanchão do lago, a minha avó de regresso do Casino e a Adelaide à sua espera com tisanas e xailes, quem sabe se meu pai acabado de falecer na clínica e daqui a nada o telefone, de início uma pausa na vivenda com a campainha a tocar-se, depois a mesma pausa na sala do rés-do-chão enquanto no quarto das criadas e no primeiro andar protestos, tropeçar de chinelas, compartimentos que se acendem de golpe, se tornam conhecidos e vão perdendo mistério ${ }^{18}$.

Para que as coisas do mundo em seu mistério provoquem a imaginação criadora de Maria Clara é necessário que esta conte com o alerta de suas faculdades sensitivas. Sua narrativa está repleta de sensações de calor, de cheiros e sons do mundo externo e do interior da sua casa que é quase todo o seu universo. Eis aqui alguns fenômenos do mundo sensível que produzem a atmosfera do entressonhar:

as persianas descidas a impedirem o calor e no entanto riscos paralelos de sol interrompidos pela passagem dos pombos, o cheiro da febre a somar-se ao cheiro de açúcar queimado, um som de bronquite humilde e o ferver de solas numa cafeteira ao lume ${ }^{19}$.

Também pode ocorrer que uma sinestesia às avessas, em que as lembranças concorrem para provocar sensações, venha a reinstaurar Maria

\footnotetext{
${ }^{18}$ ANTUNES, 2000. p. 127.

${ }^{19}$ ANTUNES, 2000. p. 94.
} 
Clara no passado do seu lar de criança: "quando penso no Estoril os ciprestes do cemitério crescem negros ao sol sinto-os sobre o telhado a roçarem-me os braços, a mexerem-me no corpo, a levarem-me consigo para os meus pais para casa"20.

A experiência fenomenológica do mundo pode instaurar ainda cenas de um cosmodrama que traz Maria Clara numa fusão erótica com os elementos do ambiente circundante. Nos fragmentos líricos abaixo há representações dessa fusão sob o influxo da vida vegetal, tantas vezes sugerido ao longo da obra:

o lago a escorrer para os canteiros dos goivos, para os degraus de tijoleira, para o alpendre da casa, ouvia soluçar fora de mim, não me ralava em que sítio, as criadas, a modista, o chofer até compreender que era eu que soluçava sem compreender o motivo das lágrimas, ou então não lágrimas, raminhos e cachos e folhas que tombavam de mim no mármore do vestíbulo, contei doze rectângulos de dois palmos de $\operatorname{lado}^{21}$;

como se tivesse saudades de haver sido árvore, cerrava a mão naquele relevo de pau e sentia a vida opaca e lenta da madeira, um sangue parecido com o meu sangue a ferver no interior de arteriazinhas secretas, se um rapaz tentava tocar-me no cinema ou no café cresciame um freixo dentro e o vento de outubro estremecia e fazia dele árvore também ${ }^{22}$.

Nesse movimento dos sentidos, a visão desempenha grande função no perceber das coisas. Uma visão sob a luz dirigida pode conceder às imagens liberdade para que se componham numa profundidade de campo em que o tempo passe a ser a medida da distância entre as posições do objeto. Assim Maria Clara pode representar o pai na sobreposição de momentos distintos de sua vida: "pensei nesse instante que um rapazinho de balão me olhava através dos anos, aproximei-me da almofada mas o rapazinho deu lugar a rugas, dentes postiços, um gesto parecido com o gesto que emudecia o advogado" ${ }^{23}$. Mas vale lembrar que é a penumbra

\footnotetext{
${ }^{20}$ ANTUNES, 2000. p. 455.

${ }^{21}$ ANTUNES, 2000. p. 389.

${ }^{22}$ ANTUNES, 2000. p. 437.

${ }^{23}$ ANTUNES, 2000. p. 159.
} 
que melhor garante a reapresentação do passado indomado que pode inclusive não ter sido. Desse modo, é no sótão, às escuras, que Maria Clara pode ver mais claramente o desfile de mortos que talvez nem tenham tido existência nessa vida:

eu no sótão do Estoril com os baús e os medalhões, nem um candeeiro aceso, nem uma luz nas

não sei se me está a ouvir, nem uma luz nas glicínias, a moradia em silêncio até à chegada do rei a Lisboa, o velhote com giz na lapela, o marido da inválida, o avô da Leopoldina, o pai do meu pai a assistir às carruagens que se alinhavam no cais, o senhor general na varanda a pedir um copo de água não pedindo água nenhuma, só o indicador no colarinho, uma barbatana em súplica, uma guelra no bigode ${ }^{24}$.

Trata-se, como se disse, de uma visão de cegos. Visão para a qual concorriam todos os sentidos, e que fora talvez, no caso de Maria Clara, treinada desde cedo através da observação do avô, cuja sensibilidade poderia até mesmo indicar "se as raízes dos freixos aumentavam na terra" 25 . Porém, enquanto o avô permanece muitas vezes acorrentado na "mina onde os cegos habitam quando não estão com a gente" ${ }^{26}$, Maria Clara penetra na profundidade do escuro para desfazer a imobilidade das coisas. E não lhe basta desenterrar crânios, é preciso interrogá-los, assim como é preciso encontrar marcas que ajudem a decifrar o mundo na imprecisão do tempo. E, uma vez aceita a provocação da matéria do mundo, é possível fazer eclodir e reverberar na noite a imagem do grito no lugar da realidade opaca do crânio. A seguir, os passos desse exercício de criação da imaginação produtiva de Maria Clara praticado muito antes da descoberta dos restos no sótão que aparentemente deflagrara sua narrativa:

as feições reduzidas a buracos num clarão de calcário, os buracos dos olhos, os buracos do nariz, o buraco da boca a aumentar um grito e em lugar do grito uma escuridão repentina, na escuridão a janela isto é os troncos dos freixos e o arrepio das palmeiras, o regresso da vassoura e o morcego a sumir-se em piruetas de jornal ao vento na lanterna do

\footnotetext{
${ }^{24}$ ANTUNES, 2000. p. 306.

${ }^{25}$ ANTUNES, 2000. p. 253.

${ }^{26}$ ANTUNES, 2000. p. 257.
} 
alpendre, o jardineiro com um escadote e uma lâmpada nova, as palmeiras cessaram de existir e o escuro empoleirou-se no armário outra vez, girava-se o comutador e continuava lá consoante os sorrisos dos mortos o verão inteiro na sala enquanto a gente em Tomar, a Ana e eu na certeza que não dando por nós os mortos aborrecidos e graves, espiávamos e os sorrisos nas molduras uma vez que era impossível não escutarem o automóvel no saibro ${ }^{27}$

Já nos últimos momentos da narrativa, Maria Clara dirige imaginariamente uma injunção à sua mãe: Não se esqueça das magnólias mãe, da árvore sobre o poço, das flores brancas na água ${ }^{28}$. Mas o que se segue, como possível atitude da mãe em atendimento à determinação da filha, indica a inaptidão sensorial daquela para perceber algo além de um círculo de trevas a sorver flores. Há na observação da mãe a demonstração de uma incapacidade de formular, nos moldes em que opera a visão de Maria Clara, a dialética do reflexo e da profundeza ${ }^{29}$, de encontrar no reflexo e nas flores sob a superfície da água a segurança das forças contrárias ao abismo do lago.

A obra de Lobo Antunes finaliza-se com Maria Clara em frente à televisão em busca de uma manifestação qualquer de afeto. Mas ela não entende bem o que se passa na tela. Talvez sua capacidade de percepção dos sinais externos não seja apropriada à recepção dos raios emitidos por um terminal de vídeo. Assim sendo, imagens em profusão transmitidas pelo aparelho não lhe serviriam como princípio de criação, tampouco lhe forneceriam elementos com o que suprir aquilo que lhe falta. Não podendo ser a narradora do espetáculo a que assiste, mas também recusando-se à observação exclusiva da experiência alheia ${ }^{30}$, resta-lhe

${ }^{27}$ ANTUNES, 2000. p. 289-290.

${ }^{28}$ ANTUNES, 2000. p. 548.

${ }^{29}$ O conceito de "dialética do reflexo e da profundeza" foi apropriado das reflexões de Bachelard sobre a habilidade plástica de Claude Monet em recuperar a calma da água parada na série das ninféias. Sobre isso ver BACHELARD, 1986. p. 3-7.

${ }^{30}$ Essas duas alternativas são na verdade apresentadas como duas hipóteses sobre o narrador pós-moderno nas reflexões de Silviano Santiago sobre o tema. Seguindo a conceituação de Santiago no julgamento da narrativa de Maria Clara, pode-se dizer que seu esforço narrativo ultrapassa a passividade prazerosa em que o narrador pós-moderno se apresenta. 
recuperar o valor da sua experiência no mundo - numa analogia com o gesto de submeter a tela ao toque - e reconstruí-lo numa revalorização de seus elementos sob a forma sublime de sua grandeza poética.

\section{Referências Bibliográficas}

ANTUNES, António Lobo. Não entres tão depressa nessa noite escura. Lisboa: Dom Quixote, 2000.

BACHELARD, Gaston. O direito de sonhar. São Paulo: Difel, 1986.

BLANCHOT, Maurice. O diário íntimo e a narrativa. In: Olivro porvir. Rio de Janeiro: Rocco, 1989. p. 192-198.

SANTIAGO, Silviano. O narrador pós-moderno. In: Nas malhas da letra. São Paulo: Companhia das Letras, 1989. p. 38-52.

SEIXO, Maria Alzira. Noite transfigurada. In: Os romances de António Lobo Antunes. Lisboa: Dom Quixote, 2002. p. 385-425. 


\section{Resumo}

Este artigo resulta de uma leitura crítica do livro Não entres tão depressa nessa noite escura, do escritor português António Lobo Antunes. Tal leitura se fez em atenção aos pequenos poemas inseridos na estrutura narrativa do romance. Levando em consideração essa mescla de enredo e poemas em prosa, a análise do texto aponta, de um lado, o sentido de incompletude da ficção contemporânea de Lobo Antunes e, de outro, a realização poética que atribui novos significados às ruínas do mundo atual. Ao acompanhar a atividade perceptiva da narradora, a análise destaca também uma forma de relação fenomenológica com as coisas do mundo que serve como fundamentação da criação poética.

\section{Résumé}

Cet article résulte de la lecture critique du livre Não entres tão depressa nessa noite escura de l'écrivain portugais António Lobo Antunes. Cette lecture a été centrée sur les petits poèmes inserés dans la structure narrative du roman. En considérant ce mélange de trame et de poèmes em prose, l'analyse du texte montre, d'un côté, le caractère d'incomplétude de la fiction contemporaine de Lobo Antunes et, de l'autre côté, la réalisation poétique qui donne des nouveaux sens aux ruines du monde actuel. En suivant l'activité perceptive de la narratrice, l'analyse met aussi en évidence une forme de relation phénoménologique avec les choses du monde qui sert de base à la creátion poétique. 